Glass transition temperatures, melting temperatures, water contact angles and dimensional precision of simple fused deposition model 3D prints and 3D printed channels constructed from a range of commercially available filaments

Elaheh Sirjani ${ }^{1}$, Peter J. Cragg ${ }^{1}$ and Marcus K. Dymond ${ }^{1 *}$

Division of Chemistry, School of Pharmacy and Biomolecular Sciences, University of Brighton, Brighton, BN2 4GL.

Contact email: M.Dymond@brighton.ac.uk

\begin{abstract}
Here we evaluate the properties of a range of commercially available 3D printer filaments that make them useful in fluid handling applications. Data relating to the glass transition temperatures, melting temperatures and melting enthalpies of the unprinted filaments are reported. In the printed state we report water contact angles and the dimensional precision of simple 3D printed objects and 3D printed channels. We also report the print settings, such as extruder temperature and build platform temperature, which enabled us to obtain the basic 3D printed objects used for testing. By making these data available we hope that other users may benefit and avoid some of the difficulties we first encountered when using novel filaments in our 3D prints, particularly when trying to construct watertight devices.
\end{abstract}

Graphical abstract
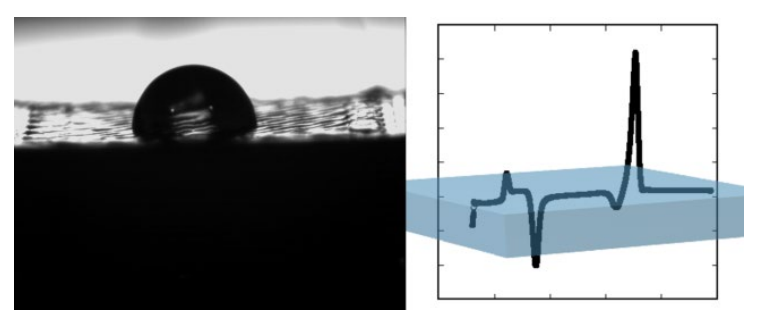

Keywords Fused deposition model 3D printing, water contact angles, glass transition temperatures, 3D print shrinkage and dimensional accuracy 


\section{Specifications Table}

\begin{tabular}{|l|l|}
\hline Subject area & Physical Chemistry \\
\hline Compounds & N/A \\
\hline Data category & Physical measurements \\
\hline Data acquisition format & $\begin{array}{l}\text { Water contact angles, glass transition temperatures, melting } \\
\text { temperatures, melting enthalpies and 3D print dimensions }\end{array}$ \\
\hline Data type & Analyzed \\
\hline Procedure & $\begin{array}{l}\text { Contact angles measured by goniometry, glass transition temperatures, } \\
\text { melting temperatures and melting enthalpies measured by differential } \\
\text { scanning calorimetry, 3D printed object and feature dimensions }\end{array}$ \\
\hline Data accessibility & Data is with this article \\
\hline
\end{tabular}




\section{Rationale}

The ready availability of consumer level fused deposition model (FDM) 3D printers has led to a rapid expansion in the number of 3D printer filaments available commercially. In addition to the commonly used polylactic acid (PLA) and acrylonitrile butadiene styrene (ABS), polymers such polyethylene terephthalate (PET), nylon and high impact polystyrene (HIPS) are available as 3D printable filaments. Filaments with high optical transparency (HD Glass or T-Glase) or environmentally friendly filaments like Biofila, a lignin-based material, can also be purchased. The relative ease of doping these thermoplastics with other materials to make composite filaments, containing materials like iron, carbon nanotubes and stainless steel, means there is a large range of 'experimental' 3D printer filaments available to the end user.

As an internet search will reveal, these experimental filaments are not always easily printed and thus many users report poor quality prints, extruder blockages and frequent printer failure. Anecdotal evidence like this tends to put new users off experimenting with novel filaments, especially if using them would invalidate the manufacturers' warranties of most 3D printers. Nevertheless, academics have begun to utilize 3D printers to make bespoke reactionware [1-4], spectroscopic devices [5-8], microfluidic devices [9-11] and labware [12]. Many of these applications, which span the chemical and biological sciences [13], use the standard ABS or PLA filaments for device construction. However, as increasingly technical devices are imagined which might, for example, incorporate liquid handling systems, heated areas or chemically modifiable surfaces, alongside lipids [14], proteins [15] and other biomolecules, experimenting with these novel 3D printer filaments becomes increasingly interesting.

Herein we report water contact angles, print shrinkage, printed channel dimensions, glass transition temperatures $\left(T_{g}\right)$, melting temperatures $\left(T_{m}\right)$ and melting enthalpies $\left(\Delta H_{m}\right)$ for a range of commercially available 3D printer filaments. The aqueous contact angle is an useful parameter for liquid handling applications, particularly in 3D printed microfluidic devices [16], since it is a measure of surface hydrophobicity. The $T_{g}$ is the temperature at which the polymer (or 3D print) transitions from a crystalline to fluid state and it is well established that introducing additives into polymers like ABS can change the $T_{\mathrm{g}}$ [17-19]. Furthermore, this parameter provides information on the upper working temperature range of the 3D print and is useful for applications at elevated temperatures, since above the $T_{\mathrm{g}}$ the integrity of the print decreases, which increases the probability of failure. Furthermore, in spectroscopic applications, even if print failure is not a problem, creep in the 3D print and the resultant shape changes decrease the comparability between experiments. Finally, we also report the measured 
dimensions of the 3D printed objects printed for each filament. Polymer shrinkage after extrusion and cooling is a well-known phenomenon in the microfabrication field, however the increase in the user base, driven by the rise in cheap FDM printers, means that those new to 3D printing are unaware of this problem. By reporting the shrinkage of the individual filaments in the $x, y$ and $z$ dimensions, as well as the printed channel dimensions for several different channel widths, we hope to make new users aware of some of the common pitfalls in FDM fabrication.

\section{Procedure}

3D Printing was performed on a MakerBot Replicator 2X Experimental 3D printer (MakerBot Industries), set up as per the manufacturer standard instructions. 3D Printable objects were designed with Autodesk 123D Design Version 1.8.34 (Autodesk Inc.) and exported as STL files, which were sliced in MakerBot Desktop version 3.8.1 and converted to X3G format for printing. All 3D prints were printed without a raft. Filament details are provided in Table 1. The best adherence to the build platform was achieved using Kapton polyimide tape (Makerbot Industries) or Blue Tape (blue masking tape, Eurocel,) or BuildTak (BuildTak), as summarized in Table 1. Extruder temperatures and build platform temperature are also shown in Table 1. Print settings for each filament that gave high quality prints (on visual inspection) are provided as supporting information. Our general approach started by using the print settings of $A B S$ as a baseline see Table $S 1$, changes to this baseline were made until satisfactory prints were achieved, as shown in Table S2. We define 'satisfactory prints' as prints as having no gaps between extruded threads, when observed by eye, and report the print settings that enabled 10 successive 3D prints to print without failure. 
Table 1 Summary of the 3D printer filaments analyzed

\begin{tabular}{|c|c|c|c|c|c|c|}
\hline Filament & Polymer/ components & Color & Manufacturer & $\begin{array}{l}\text { Extruder } \\
\text { Temp. / } \\
{ }^{\circ} \mathrm{C}\end{array}$ & $\begin{array}{c}\text { Build } \\
\text { Platform } \\
\text { Temp. } /{ }^{\circ} \mathrm{C}\end{array}$ & $\begin{array}{l}\text { Build } \\
\text { platform } \\
\text { surface }\end{array}$ \\
\hline ABS & $A B S$ & White & MakerBot & 230 & 110 & Kapton tape \\
\hline $\begin{array}{c}\text { PC-ABS Alloy } \\
\text { (Polycarbonate ABS Alloy) }\end{array}$ & Polycarbonate ABS & White & Proto-Pasta & 255 & 125 & Build Tak \\
\hline PLA & PLA & White & MakerBot & 220 & 70 & Kapton tape \\
\hline Conductive PLA & PLA/ carbon black & Black & Proto-Pasta & 230 & 50 & Blue Tape \\
\hline Biofila Linen & Lignin & Cream & Two-Bears & 220 & 70 & Blue Tape \\
\hline HIPS & Polystyrene & White & $\begin{array}{c}\text { RepRapper } \\
\text { Tech }\end{array}$ & 240 & 110 & Blue Tape \\
\hline XT- Copolyester & AM 1800 & White & ColorFabb & 240 & 70 & Blue Tape \\
\hline T-Glase & $\begin{array}{l}\text { Polyethylene } \\
\text { terephthalate }\end{array}$ & Colourless & Taulman 3D & 210 & 55 & Build Tak \\
\hline HD Glass & $\begin{array}{l}\text { Polyethylene } \\
\text { Terephthalate glycol }\end{array}$ & Colourless & Formfutura & 225 & 45 & Build Tak \\
\hline SemiFlex & $\begin{array}{c}\text { Polyurethane } \\
\text { Polyester Elastomer }\end{array}$ & White & NinjaTek & 220 & 50 & Kapton tape \\
\hline MakerBot Flexible & Polycaproyl lactone & White & MakerBot & 100 & ambient & Kapton tape \\
\hline
\end{tabular}

Determination of the $T_{g}, T_{m}$, and $\Delta H_{m}$ of 3D printer filaments

Differential scanning calorimetry (DSC) studies of FDM filaments were performed on DSC Q2000 (TA instruments) Samples (circa $10 \mathrm{mg}$ ) of filaments were placed inside a DSC pan (TZero pan, TA instruments) and lid (TZero lid, TA instruments) of known mass. An identical but empty pan and lid of known mass was used as a reference. $T_{g}, T_{m}$ and $\Delta H_{m}$ values were measured using a modulated DSC method with modulation amplitude of $\pm 1^{\circ} \mathrm{C}$, modulation time $60 \mathrm{~s}$, ramp rate $3^{\circ} \mathrm{C} / \mathrm{min}$, starting at $30^{\circ} \mathrm{C}$ and finishing at $250^{\circ} \mathrm{C}$. Two runs were recorded on each sample and measurements were made on the second run to eliminate the effect of artefacts due to surface area changes between the melting 
filaments and the bottom of the pan. Three independent repeats were performed and data show the mean arithmetic average with the standard deviation as error.

\section{Determination of water contact angles on 3D printed surfaces}

3D Printed surfaces for contact angle measurements were obtained by printing a cuboid $(9.5 \times 9.5 \times 2.5$ $\mathrm{mm}$ ) at $10 \%$ infill. The contact angles of a water droplet on the 3D printed thermoplastic surface were measured using a contact angle goniometer (OCA15 plus, firmware version SCA20). The surface of the 3D print was wiped clean with a Kimwipe before the measurements were taken. Water droplets $(5.0 \mu l)$ were dispensed at a rate of $0.50 \mu \mathrm{l} / \mathrm{s}$ from Hamilton microliter syringes (DS 500/GT, Gaslight $500 \mu \mathrm{l}$ ) fixed on the goniometer. Prior to the first experiment, syringes were filled with $18 \mathrm{~m} \Omega$ purified water (Purelab Option DV25, ELGA) and rinsed three times. Images of the droplets were taken after 10 minutes rest and at ambient temperature, in triplicate. Contact angles were calculated using both the right and left drop side according to the captive drop method [20] and averaged. Data show the average and standard deviation of each contact angle.

\section{Determination of dimensional accuracy of 3D prints}

For each filament tested, a thermoplastic cuboid $(9.5 \times 9.5 \times 2.5 \mathrm{~mm})$ and a simple cuboid $(20 \times 20 \times 2.5$ $\mathrm{mm}$ ) with 3 channels $(1 \times 1,0.5 \times 1$ and $0.25 \times 1)$ was printed using the print settings specified in Tables $1, \mathrm{~S} 1$ and $\mathrm{S} 2$. For each filament each print design was printed 3 times. The size of the final print was measured in the $\mathrm{x}, \mathrm{y}$ and $\mathrm{z}$ directions using Vernier calipers (Duratool). 3D printed channels were measured at the top, middle and bottom of the printed channel. Channel depth was determined by subtracting the measured depth of the print in the $z$ direction, at the bottom of the channel, from the measured $z$ dimension of the printed cuboid. For clarity, all dimensions measured are shown in Figure $\mathrm{S}^{* *}$. The percentage dimensional precision was calculated as $100 \% \mathrm{x}$ (print dimension/ design dimension). Data are the average measurements of three repeat prints plus/ minus the standard deviation of the mean.

\section{Data, value and validation}

Water contact angles, glass transition temperatures, melting temperatures and melting enthalpies 
Table 2 shows the water contact angles and the $T_{g}, T_{m}$ and $\Delta H_{m}$ values obtained for each of the 3D printer filaments studied. Figures S1 and S2 show examples of a DSC thermogram and a contact angle image. To confirm that the $\mathrm{T}_{\mathrm{g}}$ temperatures we obtained are reliable we compared the values we obtained for PLA and ABS to literature values for these materials.

Table 2 Glass transition temperatures, melting temperatures, melting enthalpies and water contact angles of 3D printer filaments

\begin{tabular}{|c|c|c|c|c|}
\hline Filaments & $\begin{array}{l}\text { Glass Transition } \\
\text { Temp. }\left(T_{g} /{ }^{\circ} \mathrm{C}\right) \\
\text { Average } \pm \text { s.d. }\end{array}$ & $\begin{array}{l}\text { Melting Temp. } \\
\quad\left(T_{m} /{ }^{\circ} \mathrm{C}\right. \\
\text { Average } \pm \text { s.d. }\end{array}$ & $\begin{array}{l}\text { Melting Enthalpy } \\
\left(\mathrm{Jg}^{-1}\right) \\
\text { Average } \pm \text { s.d. }\end{array}$ & $\begin{array}{r}\text { Contact angle }\left(\theta_{c}^{\circ}\right) \\
\text { Average } \pm \text { s.d. }\end{array}$ \\
\hline ABS & $106.8 \pm 1.1$ & $\#$ & $\#$ & $99.3 \pm 2.8$ \\
\hline PC-ABS Alloy & $108.4 \pm 0.2$ & \# & $\#$ & $84.6 \pm 3.0$ \\
\hline 3DXNano ABS & $106.5 \pm 0.1$ & $\#$ & $\#$ & $87.2 \pm 6.2$ \\
\hline PLA & $57.3 \pm 0.5$ & $151 \pm 2.1$ & $23.7 \pm 2.4$ & $80.4 \pm 2.1$ \\
\hline Conductive PLA & $58.9 \pm 0.8$ & $146.1 \pm 0.5$ & $9.8 \pm 1.2$ & $75.1 \pm 1.7$ \\
\hline Stainless Steel PLA & $54.8 \pm 2.5$ & $153.9 \pm 0.2$ & $12.0 \pm 0.5$ & $85.4 \pm 2.6$ \\
\hline Magnetic Iron PLA & $53.6 \pm 3.0$ & $153.3 \pm 1.0$ & $15.7 \pm 0.6$ & $84.4 \pm 3.3$ \\
\hline Carbon Fibre PLA & $58.9 \pm 0.9$ & $177.8 \pm 2.8$ & $39.6 \pm 9.3$ & $62.3 \pm 2.6$ \\
\hline Biofila Linen & $53.3 \pm 1.7$ & $153 \pm 2.4$ & $24.5 \pm 2.3$ & $74.9 \pm 3.7$ \\
\hline HIPS & $96.3 \pm 1.3$ & $\#$ & $\#$ & $112.6 \pm 3.4$ \\
\hline XT-Copolyester & $79.0 \pm 0.8$ & $\#$ & $\#$ & $92.1 \pm 2.0$ \\
\hline T-Glase & $77.7 \pm 0.7$ & $\#$ & $\#$ & $87.0 \pm 1.9$ \\
\hline HD Glass & $75.8 \pm 0.7$ & $\#$ & $\#$ & $92.3 \pm 3.6$ \\
\hline SemiFlex & $-19.2 \pm 1.3$ & $196.8 \pm 0.7$ & $1.7 \pm 0.5$ & $100.4 \pm 2.9$ \\
\hline MakerBot Flexible & $-67.3 \pm 0.1$ & $57.4 \pm 2.1$ & $64.2 \pm 9.2$ & $96.3 \pm 2.3$ \\
\hline
\end{tabular}

The $T_{g}$ of pure PLA is reported to be $58.0^{\circ} \mathrm{C}$ [21] and our value of $57.3 \pm 0.5^{\circ} \mathrm{C}$ is comparable to this. Additives are known to modify the $T_{\mathrm{g}}$ of polymers and our data show some variance in the $T_{\mathrm{g}}$ value of PLA in the presence of the different additives like iron and steel. The $T_{g}$ of $A B S$ is reported to be $109.0^{\circ} \mathrm{C}$ [22] and we obtained a value of $106.8 \pm 1.1^{\circ} \mathrm{C}$, which is in broad agreement. Overall the $\mathrm{T}_{\mathrm{g}}$ we obtained also agrees well with the values reported by manufacturers, where these are available. Similarly, we compared $T_{m}$ and $\Delta H_{m}$ to values in the literature. The $T_{m}$ for PLA is reported as $151^{\circ} \mathrm{C}$ [23] or $153^{\circ} \mathrm{C}$ [24], which agrees well with the $151 \pm 2.1^{\circ} \mathrm{C}$ we observe. Literature studies show $\Delta \mathrm{H}_{\mathrm{m}}$ for PLA lies in the 
region of 16 to $29 \mathrm{Jg}^{-1}$, depending on the number of extrusions carried out [23]. We observe $\Delta \mathrm{H}_{\mathrm{m}}=23.7$ \pm 2.4 , which lies in middle of this range. We note that the presence of some additives to PLA do change the value $T_{m}$ and $\Delta H_{m}$, notably carbon fiber, presumably due to the crystalline domains of PLA aligning with the fibers.

Next we determined the water contact angles on 3D prints made from each of the filaments. It is well established that physical features such as surface roughness and post-print finishing impact the water contact angle of polymers and these have been characterized for ABS 3D prints [16]. However, the values we report are at identical print resolutions and hence provide a good indicative value of the hydrophobicity of the final unmodified 3D printed surface and the effects of composite materials within the same polymer matrix. Under these conditions the most hydrophobic surface was HIPS, followed by Semiflex and then ABS. The most hydrophilic prints were made of carbon fiber PLA although the addition of components like steel and iron have a significant effect on surface hydrophobicity, when compared to PLA.

\section{Final dimensions of 3D printed objects}

Contraction after extrusion is a phenomenon common to many thermoplastic polymers, which due to the nature of FDM printing, can cause dimensional inaccuracies in the final 3D-printed object $[25,26]$. On the other hand the nature of FDM 3D printing, whereby a narrow strand of viscous polymer is forced through a small metal hole against a solid build-platform, can result in dimensional inaccuracy depending on the dimensions of the extruded filament. For each of the filaments we evaluated the final printed dimensions, in the $x, y$ and $z$ directions, of a 3D printed cuboid at $10 \%$ and $100 \%$ infill. Tables 3 and 4 show the data. For each of the filaments, we also evaluated the final dimensions of 3 different sized 3D printed channels at $10 \%$ and $100 \%$ infill, Tables 5 and 6.

It is clear from the data in Tables 3 and 4 that most of the filaments lead to dimensional inaccuracies in the final printed object compared to the design. Furthermore, the discrepancy between print size and design size depends on the amount of infill in the printed object. This is perhaps unsurprising as consumer level 3D printers do not monitor the final extruded dimensions of the thermoplastic print material. The flexible filaments Semiflex and Makerbot Flexible showed most shrinkage at $10 \%$ infill, notably these prints were $90 \%$ and $93 \%$ smaller than designed in the $z$ dimension. In comparison at $100 \%$ infill Semiflex and Makerbot Flexible were $100 \%$ the designed size after printing, 
whilst T-Glase shrank most significantly $(87 \%)$ in the $z$ direction. We also assessed measured the final dimensions of 3D printed channels. We evaluated three 3D printed channels of $1 \mathrm{~mm}$ depth and 2, 1 and $0.5 \mathrm{~mm}$ width, at $10 \%$ and $100 \%$ infill. Tables 5 and 6 show the final data. We found that visually discernable channel of $0.5 \times 1 \mathrm{~mm}$ could not be printed with any of the filaments, although a small depression where the channel should have been was discernable.

Overall, we found that all 3D printed channels, at $10 \%$ or $100 \%$ infill, for all filaments, were narrower than specified at the design stage. Biofila Linen and Carbon Fiber PLA gave the narrowest channels at $10 \%$ infill (65.4\% and 68.2\% design dimension) and $100 \%$ infill (69.1\% and $70.6 \%$ design dimension), with Semi Flex and PC ABS alloy providing only marginally wider channels. The remaining filaments gave rise to channels that were between 80 and $90 \%$ of the specified design at both infill densities.

Our results for channel depth show that at both $10 \%$ and $100 \%$ infill the channel depth of the 2 $x 1 \mathrm{~mm}$ and $1 \times 1 \mathrm{~mm}$ channel was deeper than specified in the CAD diagram. The percentage dimensional accuracy shows that for most filaments 3D printed channels were up to $130 \%$ deeper than designed, with a few notable exceptions like PC ABS alloy. Other exceptions were those filaments where the channel depths were not determinable (n.d.), this reflects the observation that the channels made with these filaments were very narrow, such that the calipers used to measure the depth could not be applied. This is a further reflection of lack of precision in the printed width of these filaments such that for all intents and purposes there was no continuous discernable channel present after printing. Tables 5 and 6 show the data, we were able to print a $1 \mathrm{~mm}$ wide channel with all the filaments, but a $0.5 \mathrm{~mm}$ wide channel could not be printed with all filaments.

The variation in the final printed design sizes of both cuboids and channels illustrates the complex relationship between print extrusion speeds, layer height, infill and polymer shrinkage. This is further complicated when the effects of printer wear and tear are considered. For example, over time degraded plastic can build up in the printer nozzle, which will affect the size and flow of the extruded filament. Furthermore, play in the $x$ and $y$-axes of the printer can also cause inaccuracies in the final print dimensions, which are dependent of the position of the print on the build platform. In general, our past working practice and solution to achieving 3D prints of the required dimensions has been to rescale the object and print until the desired fit is achieved. Although this may seem like an obvious solution, the data we present shows that moving to new filaments will likely require a different rescaling to be carried out for the same object in order to achieve 3D prints of the desired dimensions in different 
Received 20 Dec 2018, Revised 20 May 2019, Accepted 7 June 2019

materials. In our work where we are interested in watertight prints $[4,7]$ we find that it is worthwhile optimizing the print settings to obtain leak-free prints prior to carrying out object rescaling. 
Table 3 Dimensional precision of 3D printed thermoplastic cuboids $(9.5 \times 9.5 \times 2.5 \mathrm{~mm})$ at $10 \%$ infill

\begin{tabular}{lcccccc}
\hline & \multicolumn{2}{c}{$\mathbf{x}, \mathbf{y}, \mathbf{z}$ print dimensions $/ \mathbf{m m}$} & \multicolumn{3}{c}{ Dimensional precision (\% design size) } \\
Filament & $\mathbf{x}$ & $\mathbf{y}$ & $\mathbf{Z}$ & $\mathbf{x}$ & $\mathbf{Y}$ & $\mathbf{z}$ \\
& Average \pm s.d. & Average \pm s.d. & Average \pm s.d. & & & \\
\hline ABS & $9.40 \pm 0.05$ & $9.38 \pm 0.06$ & $2.37 \pm 0.04$ & 98.98 & 98.70 & 94.80 \\
PC ABS Alloy & $9.42 \pm 0.07$ & $9.51 \pm 0.03$ & $2.36 \pm 0.02$ & 99.19 & 100.11 & 94.40 \\
3DX Nano ABS & $9.39 \pm 0.09$ & $9.47 \pm 0.07$ & $2.30 \pm 0.04$ & 98.81 & 99.65 & 92.13 \\
PLA & $9.42 \pm 0.00$ & $9.42 \pm 0.00$ & $2.50 \pm 0.00$ & 99.16 & 99.16 & 100.00 \\
Conductive PLA & $9.37 \pm 0.01$ & $9.50 \pm 0.00$ & $2.59 \pm 0.02$ & 98.60 & 100.00 & 103.47 \\
Stainless Steel PLA & $9.38 \pm 0.12$ & $9.58 \pm 0.02$ & $2.47 \pm 0.21$ & 98.70 & 100.88 & 98.80 \\
Magnetic Iron PLA & $9.34 \pm 0.01$ & $9.51 \pm 0.01$ & $2.58 \pm 0.03$ & 98.28 & 100.07 & 103.07 \\
Carbon Fiber PLA & $9.50 \pm 0.10$ & $9.50 \pm 0.05$ & $2.64 \pm 0.04$ & 99.96 & 100.04 & 105.47 \\
Biofila Linen & $9.44 \pm 0.10$ & $9.55 \pm 0.01$ & $2.31 \pm 0.06$ & 99.33 & 100.49 & 92.40 \\
HIPS & $9.35 \pm 0.02$ & $9.42 \pm 0.04$ & $2.34 \pm 0.02$ & 98.39 & 99.16 & 93.47 \\
XT- Copolyester & $9.31 \pm 0.03$ & $9.22 \pm 0.06$ & $2.34 \pm 0.01$ & 98.04 & 97.02 & 93.60 \\
T-Glase & $9.25 \pm 0.03$ & $9.23 \pm 0.04$ & $2.45 \pm 0.01$ & 97.33 & 97.19 & 97.87 \\
Semi Flex & $8.91 \pm 0.01$ & $8.94 \pm 0.01$ & $2.27 \pm 0.02$ & 93.82 & 94.14 & 90.93 \\
HD glass & $9.21 \pm 0.03$ & $9.30 \pm 0.03$ & $2.40 \pm 0.00$ & 98.25 & 98.28 & 100.00 \\
MakerBot Flexible & $9.13 \pm 0.02$ & $9.13 \pm 0.01$ & $2.35 \pm 0.01$ & 96.14 & 96.14 & 93.87
\end{tabular}


Table 4 Dimensional precision of 3D printed thermoplastic cuboids $(9.5 \times 9.5 \times 2.5 \mathrm{~mm})$ at $100 \%$ infill

\begin{tabular}{lcccccc}
\hline \multirow{2}{*}{ Filament } & \multicolumn{2}{c}{$\mathbf{x}, \mathbf{y}, \mathbf{z}$ print dimensions $\mathbf{m m}$} & \multicolumn{3}{c}{ Dimensional precision (\% design size) } \\
& $\mathbf{x}$ & $\mathbf{y}$ & $\mathbf{z}$ & $\mathbf{x}$ & $\mathbf{y}$ & $\mathbf{z}$ \\
& Average \pm s.d. & Average \pm s.d. & Average \pm s.d. & & & \\
\hline ABS & $9.45 \pm 0.02$ & $9.45 \pm 0.01$ & $2.50 \pm 0.00$ & 99.51 & 99.44 & 100.00 \\
PC ABS Alloy & $9.00 \pm 0.00$ & $9.00 \pm 0.00$ & $2.25 \pm 0.00$ & 94.74 & 94.74 & 90.00 \\
3DX Nano ABS & $9.17 \pm 0.02$ & $9.17 \pm 0.01$ & $2.50 \pm 0.00$ & 96.49 & 96.49 & 100.00 \\
PLA & $9.45 \pm 0.00$ & $9.45 \pm 0.00$ & $2.50 \pm 0.00$ & 99.47 & 99.47 & 100.00 \\
Conductive PLA & $9.33 \pm 0.03$ & $9.33 \pm 0.03$ & $2.50 \pm 0.00$ & 98.25 & 98.25 & 100.00 \\
Stainless Steel PLA & $9.33 \pm 0.03$ & $9.33 \pm 0.03$ & $2.25 \pm 0.00$ & 98.25 & 98.25 & 90.00 \\
Magnetic Iron PLA & $9.00 \pm 0.00$ & $9.00 \pm 0.00$ & $2.33 \pm 0.03$ & 94.74 & 94.74 & 93.33 \\
Carbon Fiber PLA & $9.42 \pm 0.02$ & $9.33 \pm 0.03$ & $2.50 \pm 0.00$ & 99.16 & 98.25 & 100.00 \\
Biofila Linen & $9.25 \pm 0.00$ & $9.25 \pm 0.00$ & $2.93 \pm 0.06$ & 97.37 & 97.37 & 117.07 \\
HIPS & $9.25 \pm 0.00$ & $9.25 \pm 0.00$ & $2.57 \pm 0.11$ & 97.37 & 97.37 & 102.67 \\
XT- Copolyester & $9.00 \pm 0.00$ & $9.17 \pm 0.04$ & $2.60 \pm 0.09$ & 94.74 & 96.49 & 104.00 \\
T-Glase & $9.00 \pm 0.00$ & $9.00 \pm 0.00$ & $2.07 \pm 0.13$ & 94.74 & 94.74 & 82.80 \\
Semi Flex & $9.25 \pm 0.00$ & $9.25 \pm 0.00$ & $2.50 \pm 0.00$ & 97.37 & 97.37 & 100.00 \\
HD Glass & $9.33 \pm 0.03$ & $9.34 \pm 0.03$ & $2.50 \pm 0.00$ & 98.25 & 98.28 & 100.00 \\
MakerBot Flexible & $9.42 \pm 0.01$ & $9.42 \pm 0.01$ & $2.50 \pm 0.00$ & 99.12 & 99.16 & 100.00
\end{tabular}

n.d. indicates prints where the channel was not continuously well defined along the length of the 3D print. 
Table 5 Dimensional precision of 3D printed channels at $10 \%$ infill

\begin{tabular}{|c|c|c|c|c|c|c|}
\hline \multirow[b]{2}{*}{ Filament } & \multicolumn{2}{|c|}{ Measured channel width /mm } & \multicolumn{2}{|c|}{ Measured channel depth / $\mathrm{mm}$} & \multicolumn{2}{|c|}{ Dimensional precision (\% design size $\mathrm{w} \times \mathrm{d}$ ) } \\
\hline & $\begin{array}{c}2 \times 1 \mathrm{~mm} \\
\text { Average } \pm \text { s.d. }\end{array}$ & $\begin{array}{c}1 \times 1 \mathrm{~mm} \\
\text { Average } \pm \text { s.d. }\end{array}$ & $\begin{array}{c}2 \times 1 \mathrm{~mm} \\
\text { Average } \pm \text { s.d. }\end{array}$ & $\begin{array}{c}1 \times 1 \mathrm{~mm} \\
\text { Average } \pm \text { s.d. }\end{array}$ & $2 \times 1 \mathrm{~mm}$ & $1 \times 1 \mathrm{~mm}$ \\
\hline ABS & $1.83 \pm 0.02$ & $0.87 \pm 0.06$ & $1.18 \pm 0.02$ & $1.21 \pm 0.02$ & $91.6 \times 115.2$ & $86.7 \times 120.5$ \\
\hline PC ABS Alloy & $1.47 \pm 0.07$ & $0.43 \pm 0.07$ & $1.21 \pm 0.05$ & $0.81 \pm 0.4$ & $73.6 \times 121.0$ & $43.0 \times 81.5$ \\
\hline 3DX Nano ABS & $1.65 \pm 0.06$ & $0.66 \pm 0.04$ & $1.11 \pm 0.03$ & $1.32 \pm 0.03$ & $82.6 \times 111.2$ & $66.4 \times 131.7$ \\
\hline PLA & $1.67 \pm 0.04$ & $0.67 \pm 0.08$ & $1.24 \pm 0.09$ & $1.31 \pm 0.09$ & $83.7 \times 124.3$ & $66.7 \times 130.7$ \\
\hline Conductive PLA & $1.52 \pm 0.07$ & $0.62 \pm 0.03$ & $1.19 \pm 0.03$ & $1.17 \pm 0.06$ & $76.0 \times 118.8$ & $62.3 \times 117.2$ \\
\hline Stainless Steel PLA & $1.41 \pm 0.13$ & n.d. & $1.17 \pm 0.13$ & n.d. & $70.7 \times 117.3$ & n.d. \\
\hline Magnetic Iron PLA & $1.54 \pm 0.16$ & $0.51 \pm 0.11$ & $1.35 \pm 0.06$ & n.d. & $77.2 \times 113.5$ & n.d. \\
\hline Carbon Fiber PLA & $1.37 \pm 0.15$ & n.d. & $1.42 \pm 0.11$ & n.d. & $68.2 \times 142.1$ & n.d. \\
\hline Biofila Linen & $1.31 \pm 0.10$ & n.d. & $1.23 \pm 0.12$ & n.d. & $65.4 \times 122.8$ & n.d. \\
\hline HIPS & $1.68 \pm 0.03$ & $0.71 \pm 0.04$ & $1.21 \pm 0.12$ & $1.28 \pm 0.13$ & $83.8 \times 124.7$ & $70.7 \times 127.5$ \\
\hline XT-Copolyester & $1.69 \pm 0.04$ & $0.64 \pm 0.04$ & $1.22 \pm 0.02$ & $1.24 \pm 0.05$ & $84.6 \times 122.3$ & $64.3 \times 124.0$ \\
\hline T-Glase & $1.75 \pm 0.08$ & $0.66 \pm 0.03$ & $1.16 \pm 0.11$ & $1.22 \pm 0.12$ & $87.6 \times 116.3$ & $65.6 \times 122.7$ \\
\hline Semi Flex & $1.47 \pm 0.18$ & $0.55 \pm 0.06$ & $1.36 \pm 0.12$ & n.d. & $73.4 \times 136$ & n.d. \\
\hline HD Glass & $1.64 \pm 0.42$ & $0.64 \pm 0.08$ & $1.11 \pm 0.04$ & n.d. & $82.3 \times 111.3$ & $63.5 \times$ n.d. \\
\hline MakerBot Flexible & $1.79 \pm 0.07$ & $0.54 \pm 0.06$ & $1.15 \pm 0.05$ & $1.10 \pm 0.25$ & $89.3 \times 114.8$ & $53.8 \times 110.3$ \\
\hline
\end{tabular}


Table 6 Dimensional precision of 3D printed channels at $100 \%$ infill

\begin{tabular}{|c|c|c|c|c|c|c|}
\hline \multirow{3}{*}{ Filament } & \multicolumn{2}{|c|}{ Measured channel width /mm } & \multicolumn{2}{|c|}{ Measured channel depth / mm } & \multicolumn{2}{|c|}{ Dimensional precision (\% design size $\mathrm{w} \times \mathrm{d}$ ) } \\
\hline & $2 \times 1 \mathrm{~mm}$ & $1 \times 1 \mathrm{~mm}$ & $2 \times 1 \mathrm{~mm}$ & $1 \times 1 \mathrm{~mm}$ & $2 \times 1 \mathrm{~mm}$ & $1 \times 1 \mathrm{~mm}$ \\
\hline & Average \pm s.d. & Average \pm s.d. & Average \pm s.d. & Average \pm s.d. & & \\
\hline ABS & $1.62 \pm 0.08$ & $0.73 \pm 0.06$ & $1.24 \pm 0.06$ & $1.27 \pm 0.09$ & $80.8 \times 124.0$ & $73.0 \times 126.5$ \\
\hline PC ABS Alloy & $1.42 \pm 0.12$ & n.d. & $1.21 \pm 0.21$ & n.d. & $71.2 \times 120.5$ & n.d. \\
\hline 3DX Nano ABS & $1.66 \pm 0.04$ & $0.64 \pm 0.03$ & $1.17 \pm 0.05$ & $1.35 \pm 0.03$ & $82.8 \times 116.8$ & $66.2 \times 134.7$ \\
\hline PLA & $1.72 \pm 0.07$ & $0.71 \pm 0.05$ & $1.29 \pm 0.05$ & $1.30 \pm 0.05$ & $86.1 \times 128.5$ & $70.1 \times 129.7$ \\
\hline Conductive PLA & $1.59 \pm 0.08$ & $0.62 \pm 0.07$ & $1.14 \pm 0.07$ & $1.31 \pm 0.08$ & $79.6 \times 114.0$ & $61.6 \times 130.8$ \\
\hline Stainless Steel PLA & $1.48 \pm 0.11$ & n.d. & $1.11 \pm 0.15$ & n.d. & $73.9 \times 111.3$ & n.d. \\
\hline Magnetic Iron PLA & $1.54 \pm 0.16$ & $0.49 \pm 0.06$ & $1.16 \pm 0.04$ & $1.175 \pm 0.08$ & $77.1 \times 116.2$ & $49.6 \times 117.5$ \\
\hline Carbon Fiber PLA & $1.39 \pm 0.17$ & n.d. & $1.35 \pm 0.11$ & n.d. & $69.6 \times 135.2$ & n.d. \\
\hline Biofila Linen & $1.40 \pm 0.10$ & n.d. & $1.17 \pm 0.03$ & n.d. & $70.1 \times 117.2$ & n.d. \\
\hline HIPS & $1.71 \pm 0.03$ & $0.77 \pm 0.03$ & $1.23 \pm 0.06$ & $1.22 \pm 0.07$ & $85.7 \times 121.8$ & $76.7 \times 121.7$ \\
\hline XT- Copolyester & $1.65 \pm 0.03$ & $0.65 \pm 0.03$ & $1.21 \pm 0.05$ & $1.26 \pm 0.03$ & $82.3 \times 121.2$ & $64.7 \times 126.2$ \\
\hline T-Glase & $1.72 \pm 0.10$ & $0.65 \pm 0.03$ & $1.21 \pm 0.04$ & $1.23 \pm 0.09$ & $86.2 \times 120.7$ & $65.1 \times 123.3$ \\
\hline Semi Flex & $1.42 \pm 0.13$ & $0.67 \pm 0.08$ & $1.24 \pm 0.09$ & $1.11 \pm 0.25$ & $71.1 \times 123.7$ & $67.4 \times 110.5$ \\
\hline HD Glass & $1.66 \pm 0.05$ & $0.68 \pm 0.06$ & $1.18 \pm 0.03$ & $1.19 \pm 0.05$ & $83.2 \times 118.2$ & $68.0 \times 119.0$ \\
\hline MakerBot Flexible & $1.77 \pm 0.13$ & $0.62 \pm 0.16$ & $1.11 \pm 0.12$ & $1.09 \pm 0.15$ & $88.3 \times 110.5$ & $61.8 \times 108.5$ \\
\hline
\end{tabular}




\section{Acknowledgements}

The authors thank the School of Pharmacy and Biological Sciences at the University of Brighton for Startup funding for MKD and for funding the PhD studentship of ES.

\section{Appendix A: Supplementary Materials}

Supplementary material associated with this article can be found, in the online version, at doi:

\section{References}

1. Kitson PJ, Marshall RJ, Long D, Forgan RS, Cronin L. 2014 3D Printed High-Throughput Hydrothermal Reactionware for Discovery, Optimization, and Scale-Up. Angew. Chemie Int. Ed. 53, $12723-12728$.

2. Kitson PJ, Symes MD, Dragone V, Cronin L. 2013 Combining 3D printing and liquid handling to produce user-friendly reactionware for chemical synthesis and purification. Chem. Sci. 4, 30993103. (doi:10.1039/c3sc51253c)

3. Dragone V, Sans V, Rosnes MH, Kitson PJ, Cronin L. 2013 3D-printed devices for continuous-flow organic chemistry. Beilstein J. Org. Chem. 9, 951-959. (doi:10.3762/bjoc.9.109)

4. Wei Y, Mayoral-Delgado I, Stewart NA, Dymond MK. 2018 Macromolecular crowding and membrane binding proteins: the case of phospholipase A1. Chem. Phys. Lipids (doi:10.1016/J.CHEMPHYSLIP.2018.12.006)

5. Grasse EK, Torcasio MH, Smith AW. 2016 Teaching UV-Vis Spectroscopy with a 3D-Printable Smartphone Spectrophotometer. J. Chem. Educ. 93. (doi:10.1021/acs.jchemed.5b00654)

6. Brisendine JM, Mutter AC, Cerda JF, Koder RL. 2013 A three-dimensional printed cell for rapid, low-volume spectroelectrochemistry. Anal. Biochem. 439, 1-3. (doi:10.1016/j.ab.2013.03.036)

7. Pisaruka J, Dymond MK. 2016 A low volume 3D-printed temperature-controllable cuvette for UV visible spectroscopy. Anal. Biochem. 510, 52-55. (doi:10.1016/j.ab.2016.07.019)

8. Achilli E et al. 2016 3D-printed photo-spectroelectrochemical devices for in situ and in operando X-ray absorption spectroscopy investigation. J. Synchrotron Rad. 23, 622-628.

9. Gowers SAN, Curto VF, Seneci CA, Wang C, Anastasova S, Vadgama P, Yang GZ, Boutelle MG. 2015 3D Printed Microfluidic Device with Integrated Biosensors for Online Analysis of Subcutaneous Human Microdialysate. Anal. Chem. 87. (doi:10.1021/acs.analchem.5b01353) 
10. Lee W, Kwon D, Choi W, Jung GY, Jeon S. 2015 3D-printed microfluidic device for the detection of pathogenic bacteria using size-based separation in helical channel with trapezoid cross-section. Sci. Rep. 5. (doi:10.1038/srep07717)

11. Bishop GW, Satterwhite-Warden JE, Kadimisetty K, Rusling JF. 2016 3D-printed bioanalytical devices. Nanotechnology 27. (doi:10.1088/0957-4484/27/28/284002)

12. Tyson AL, Hilton ST, Andreae LC. 2015 Rapid, simple and inexpensive production of custom 3D printed equipment for large-volume fluorescence microscopy. Int. J. Pharm. 494, 651-656. (doi:10.1016/j.ijpharm.2015.03.042)

13. Chen C, Erkal JL, Gross BC, Lockwood SY, Spence DM. 2014 Evaluation of 3D Printing and Its Potential Impact on Biotechnology and the Chemical Sciences. Anal. Chem. 86, 3240-3253.

14. Burrell J, Dymond MK, Gillams RJ, Parker DJ, Langley GJ, Labrador A, Nylander T, Attard GS. 2017 Using Curvature Power to Map the Domain of Inverse Micellar Cubic Phases: The Case of Aliphatic Aldehydes in 1,2-Dioleoyl-sn-glycero-3-phosphoethanolamine. Langmuir 33. (doi:10.1021/acs.langmuir.7b02998)

15. Tsaloglou M-N, Attard GS, Dymond MK. 2011 The effect of lipids on the enzymatic activity of 6phosphofructo-1-kinase from B. stearothermophilus. Chem. Phys. Lipids 164, 713-21. (doi:10.1016/j.chemphyslip.2011.08.003)

16. McCullough EJ, Yadavalli VK. 2013 Surface modification of fused deposition modeling ABS to enable rapid prototyping of biomedical microdevices. J. Mater. Process. Technol. 213, 947-954. (doi:10.1016/j.jmatprotec.2012.12.015)

17. Huang YJ, Horng JC. 1998 Effects of thermoplastic additives on mechanical properties and glass transition temperatures for styrene-crosslinked low-shrink polyester matrices. Polymer (Guildf). 39, 3683-3695. (doi:10.1016/S0032-3861(97)10280-4)

18. Mauerer O. 2005 New reactive, halogen-free flame retardant system for epoxy resins. Polym. Degrad. Stab. 88, 70-73. (doi:10.1016/j.polymdegradstab.2004.01.027)

19. Torrado AR, Shemelya CM, English JD, Lin Y, Wicker RB, Roberson DA. 2015 Characterizing the effect of additives to ABS on the mechanical property anisotropy of specimens fabricated by material extrusion 3D printing. Addit. Manuf. 6, 16-29. (doi:10.1016/j.addma.2015.02.001)

20. Kwok DY, Neumann AW. 1999 Contact angle measurement and contact angle interpretation. Adv. Colloid Interface Sci. 81, 167-249. (doi:10.1016/S0001-8686(98)00087-6)

21. Martin O, Avérous L. 2001 Poly(lactic acid): Plasticization and properties of biodegradable multiphase systems. Polymer (Guildf). 42, 6209-6219. (doi:10.1016/S0032-3861(01)00086-6) 
22. Sanaeepur H, Amooghin AE, Moghadassi A, Kargari A. 2011 Preparation and characterization of acrylonitrile-butadiene-styrene/poly(vinyl acetate) membrane for $\mathrm{CO} 2$ removal. Sep. Purif. Technol. 80, 499-508. (doi:http://dx.doi.org/10.1016/j.seppur.2011.06.003)

23. Richert J, Stepczyńska M, Karasiewicz T, Moraczewski K, Żenkiewicz M, Rytlewski P. 2009 Characterisation of multi-extruded poly(lactic acid). Polym. Test. 28, 412-418. (doi:10.1016/j.polymertesting.2009.01.012)

24. Carrasco F, Pagès P, Gámez-Pérez J, Santana OO, Maspoch ML. 2009 Processing of poly(lactic acid): Characterization of chemical structure, thermal stability and mechanical properties. Polym. Degrad. Stab. 95, 116-125. (doi:10.1016/j.polymdegradstab.2009.11.045)

25. Dao Q, Frimodig JC, Le HN, Li XZ, Putnam SB, Golda K, Foyos J, Noorani R, Fritz B. 1999 Calculation of Shrinkage Compensation Factors for Rapid Prototyping (FDM 1650). Comput. Appl. Eng. Educ. 7, 186-195. (doi:10.1002/(SICI)1099-0542(1999)7:3<186::AID-CAE7>3.0.CO;2-Q)

26. Nuñez PJ, Rivas A, García-Plaza E, Beamud E, Sanz-Lobera A. 2015 Dimensional and Surface Texture Characterization in Fused Deposition Modelling (FDM) with ABS plus. Procedia Eng. 132, 856-863. (doi:10.1016/j.proeng.2015.12.570) 